\title{
Crystal Structure of Apraclonidine Hydrochloride
}

\author{
Noriaki Hirayama \\ Basic Medical Science and Molecular Medicine, Tokai University School of Medicine, 143 Shimokasuya, Isehara, \\ Kanagawa 259-1193, Japan \\ Correspondence should be addressed to Noriaki Hirayama; hirayama@is.icc.u-tokai.ac.jp
}

Received 12 May 2013; Accepted 5 September 2013

Academic Editors: M. Akkurt, L. R. Gomes, E. D. Lowe, and P. M. Matias

Copyright (C) 2013 Noriaki Hirayama. This is an open access article distributed under the Creative Commons Attribution License, which permits unrestricted use, distribution, and reproduction in any medium, provided the original work is properly cited.

Apraclonidine is used for the treatment of postsurgical elevated intraocular pressure. The crystal structure of its hydrochloride, $\mathrm{C}_{9} \mathrm{H}_{10} \mathrm{Cl}_{2} \mathrm{~N}_{4} \cdot \mathrm{HCl}$, was determined by X-ray analysis. The crystal belongs to space group $P 2_{1} / n$ with the cell dimensions $a=$ 9.665(10), $b=11.8624(14), c=10.5675(11) \AA$, and $\beta=92.199(9)^{\circ}$. The final $R$ (all reflections) value is 0.053 . Apraclonidine has a more twisted structure than its related drug of clonidine. The nitrogen atom bridging the two rings is protonated.

\section{Introduction}

Apraclonidine (2,6-dichloro- $\mathrm{N}^{1}$-(4,5-dihydro-1H-imidazol2-yl)-1,4-benzenediamine) is a potent $\alpha$-adrenergic agent similar to clonidine. The chemical structures of apraclonidine hydrochloride and clonidine are compared in Figure 1. Apraclonidine reduces aqueous humor formation. In clinical evaluation in the treatment of intraocular pressure, Robin et al. have showed that apraclonidine is effective in preventing the acute large postoperative intraocular pressure rise associated with argon laser iridotomy [1]. Apraclonidine is now used widely for the treatment of postsurgical elevated intraocular pressure. The additional amino group in apraclonidine makes it more polar than clonidine and reduces the penetration through the blood-brain barrier. Therefore, the pharmacological profile of apraclonidine is characterized by peripheral than central effects. Apraclonidine hydrochloride is clinically used now, but the crystal structure has not been determined yet. Therefore, the X-ray analysis of this drug was undertaken to disclose the inherent three-dimensional structure.

\section{Method}

Apraclonidine hydrochloride was purchased from SigmaAldrich Co. The single crystals of the compound were grown from a methanol solution. A colorless platelet crystal with the size of $0.35 \times 0.30 \times 0.15 \mathrm{~mm}$ was mounted on a glass fiber and used for data collection. The structure was solved by direct methods, and non- $\mathrm{H}$ atoms were refined by a full-matrix least squares method with anisotropic temperature factors. Positions of $\mathrm{H}$-atoms attached to carbon and nitrogen atoms were geometrically calculated and located from difference Fourier synthesis, respectively. All $\mathrm{H}$-atoms were refined by the riding model. The crystal and experimental data are given in Table 1 .

\section{Results and Discussion}

An ORTEP drawing [2] of apraclonidine hydrochloride is shown in Figure 2. Selected bond lengths, bond angles, torsion angles, and possible hydrogen bonds in the crystal structure are given in Table 2. Bond lengths and angles are within the expected ranges. The dihedral angle between the least squares planes of the phenyl and imidazolidine rings is $86.65(5)^{\circ}$. In clonidine hydrochloride [3], the angle is $74.7^{\circ}$. The C1-N1-C7-N3 torsion angle in apraclonidine is $168.2(1)^{\circ}$ and the corresponding angle in clonidine $178^{\circ}$. It means that in apraclonidine the imidazolidine ring is more twisted around the $\mathrm{N} 1-\mathrm{Cl}$ bond than that in clonidine. The exocyclic bond angles around the $\mathrm{C} 7$ atom are slightly asymmetrical with the N1-C7-N3 and N1-C7-N4 angles being 122.8(1) and 
TABLE 1: Crystal and experimental data.

\begin{tabular}{|c|c|}
\hline Formula: $\mathrm{C}_{9} \mathrm{H}_{10} \mathrm{Cl}_{2} \mathrm{~N}_{4} \cdot \mathrm{HCl}$ & Formula weight $=281.57$ \\
\hline Crystal system: monoclinic & Space group: $P 2_{1} / n$ \\
\hline \multicolumn{2}{|l|}{$Z=4$} \\
\hline$a=9.6615(10) \AA$ & $b=11.8624(14) \AA$ \\
\hline$c=10.5675(11) \AA$ & $\beta=92.199(9)^{\circ}$ \\
\hline$V=1210.2(2) \AA^{3}$ & $D_{x}=1.545 \mathrm{~g} / \mathrm{cm}^{3}$ \\
\hline $\begin{array}{l}\text { No. of observations } \\
(I>2.00 \sigma(I))=1873\end{array}$ & $\theta_{\max }=68.20^{\circ}$ with $\mathrm{Cu} \mathrm{K} \alpha$ \\
\hline$R(I>2.00 \sigma(I))=0.048$ & $(\Delta / \sigma)_{\max }=0.000$ \\
\hline$(\Delta \rho)_{\max }=0.48 \mathrm{e} / \AA^{3}$ & $(\Delta \rho)_{\min }=-0.53 \mathrm{e} / \AA^{3}$ \\
\hline Measurement: Rigaku & Program system: CrystalStructure \\
\hline RAXIS-RAPID & $4.0 .1[5]$ \\
\hline $\begin{array}{l}\text { Structure determination: } \\
\text { SIR92 [6] }\end{array}$ & Refinement: full-matrix \\
\hline
\end{tabular}<smiles>Nc1cc(Cl)c([NH+]=C2NCCN2)c(Cl)c1</smiles>

(a)<smiles>Clc1cccc(Cl)c1N=C1NCCN1</smiles>

(b)
Figure 1: Chemical diagrams of apraclonidine hydrochloride (a) and clonidine (b).

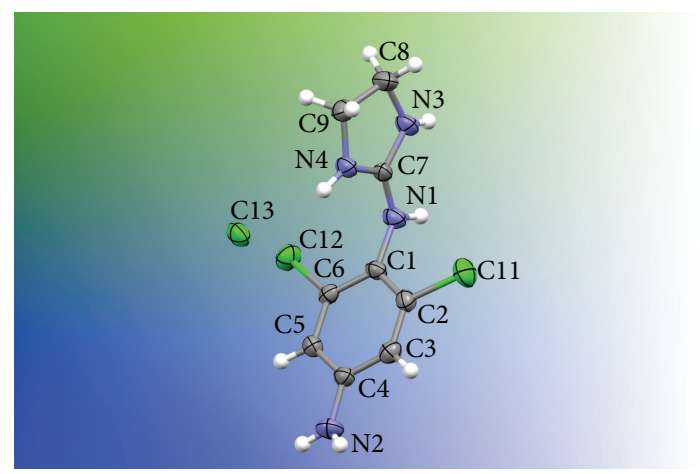

FIGURE 2: ORTEP structure of apraclonidine hydrochloride, showing $50 \%$ probability ellipsoids.

$125.6(1)^{\circ}$, respectively. There are five intermolecular hydrogen bonds in the crystal as illustrated in Figure 3 drawn by Mercury [4]. All nitrogen atoms are engaged in hydrogen bonds with the chloride ion. Although the intermolecular distance between the $\mathrm{N} 2$ and $\operatorname{Cl}[x+1 / 2,-y+1 / 2, z+1 / 2]$ atoms is 3.132(1) $\AA$, no significant electron density corresponding to the hydrogen atom was observed between the two atoms on the difference Fourier map. On the other hand, two electron density peaks corresponding to the $\mathrm{H} 2$ and $\mathrm{H} 3$ atoms which are bonded to the $\mathrm{N} 2$ atom were located from the difference map. The relevant geometrical parameters shown in Table 2 indicate that these two $\mathrm{N} 2 \cdots \mathrm{Cl} 3$ contacts should be regarded
TABLE 2: Geometrical parameters.

(a) Selected bond lengths $(\AA)$, bond angles $\left({ }^{\circ}\right)$ and torsion angles $\left({ }^{\circ}\right)$

\begin{tabular}{lc}
\hline Cl1-C2 & $1.730(1)$ \\
N1-C1 & $1.420(2)$ \\
N2-C4 & $1.355(2)$ \\
N3-C8 & $1.448(2)$ \\
N4-C9 & $1.463(2)$ \\
Cl2-C6 & $1.741(1)$ \\
N1-C7 & $1.329(2)$ \\
N3-C7 & $1.325(2)$ \\
N4-C7 & $1.320(2)$ \\
\hline Cl1-C2-C1 & $118.43(9)$ \\
Cl2-C6-C1 & $118.76(9)$ \\
N1-C1-C2 & $121.4(1)$ \\
N1-C1-C6 & $122.0(1)$ \\
N1-C7-N3 & $122.8(1)$ \\
N2-C4-C5 & $120.1(1)$ \\
C7-N3-C8 & $111.5(1)$ \\
C7-N4-C9 & $111.0(1)$ \\
Cl1-C2-C3 & $119.09(10)$ \\
Cl2-C6-C5 & $118.08(8)$ \\
C1-N1-C7 & $122.8(1)$ \\
N1-C7-N4 & $125.6(1)$ \\
N2-C4-C3 & $121.6(1)$ \\
N3-C7-N4 & $111.6(1)$ \\
N3-C8-C9 & $103.0(1)$ \\
N4-C9-C8 & $102.9(1)$ \\
\hline C7-N1-C1-C2 & $-86.6(1)$ \\
C1-N1-C7-N3 & $168.2(1)$ \\
C8-N3-C7-N1 & $177.1(1)$ \\
N1-C1-C2-Cl1 & $2.1(2)$ \\
C7-N1-C1-C6 & $96.2(1)$ \\
C1-N1-C7-N4 $29-N 4-C 7-N 1 ~$ & $-12.2(2)$ \\
N1-C1-C6-Cl2 & $-177.9(1)$ \\
\hline & $-4.9(2)$ \\
\hline
\end{tabular}

(b) Possible hydrogen bonds

\begin{tabular}{lcccccc}
\hline Donor & $\mathrm{H}$ & Acceptor & $\begin{array}{c}\mathrm{D} \cdots \mathrm{A} \\
(\AA)\end{array}$ & $\begin{array}{c}\mathrm{D}-\mathrm{H} \\
(\AA)\end{array}$ & $\begin{array}{c}\mathrm{H} \cdots \mathrm{A} \\
(\AA)\end{array}$ & $\begin{array}{c}\mathrm{D}-\mathrm{H} \cdots \mathrm{A} \\
\left({ }^{\circ}\right)\end{array}$ \\
\hline $\mathrm{N} 1$ & $\mathrm{H} 5$ & $\mathrm{Cl} 3[\mathrm{I}]$ & $3.226(1)$ & 0.90 & 2.38 & 157 \\
$\mathrm{~N} 2$ & $\mathrm{H} 2$ & $\mathrm{Cl} 3[\mathrm{II}]$ & $3.418(1)$ & 0.80 & 2.65 & 162 \\
$\mathrm{~N} 2$ & $\mathrm{H} 3$ & $\mathrm{Cl} 3[\mathrm{III}]$ & $3.400(2)$ & 0.94 & 2.52 & 156 \\
$\mathrm{~N} 3$ & $\mathrm{H} 7$ & $\mathrm{Cl} 3[\mathrm{I}]$ & $3.338(1)$ & 0.79 & 2.67 & 144 \\
$\mathrm{~N} 4$ & $\mathrm{H} 6$ & $\mathrm{Cl} 3$ & $3.213(1)$ & 0.83 & 2.42 & 163 \\
\hline
\end{tabular}

Symmetry operators:

[I] $x-1 / 2,-y+1 / 2, z-1 / 2$.

[II] $x-1 / 2,-y+1 / 2, z+1 / 2$.

[III] $-x+3 / 2, y+1 / 2,-z+3 / 2$.

as weak hydrogen bonds. The $\mathrm{N} 3 \cdots \mathrm{Cl} 3$ hydrogen bond is also regarded as a rather weak hydrogen. In clonidine, however, N3 is not engaged in hydrogen bonding. Moreover, the N1 atom in clonidine forms a stronger hydrogen bond with 


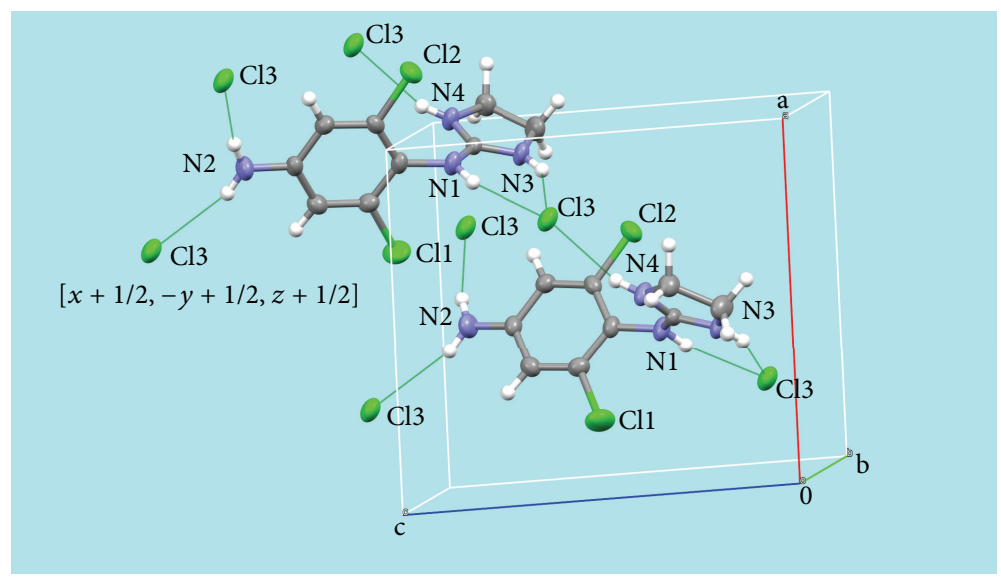

Figure 3: Packing diagram. Thin green lines denote intermolecular hydrogen bonds.

the chloride ion with the $\mathrm{N} \cdots \mathrm{Cl}$ distance being $3.09 \AA$. The corresponding hydrogen bond in apraclonidine, however, is not so strong with the $\mathrm{N} \cdots \mathrm{Cl}$ distance of 3.226(1) $\AA$.

The Crystallographic Information Files (CIF) are given as Supplementary Material available online at http://dx.doi.org/ $10.1155 / 2013 / 249672$.

\section{Concluding Remarks}

The molecular and crystal structures of apraclonidine hydrochloride were determined by X-ray analysis. Apraclonidine has a more twisted structure than its related drug of clonidine. The significant different patterns of the intermolecular hydrogen bonds observed in the crystals of apraclonidine hydrochloride and clonidine hydrochloride may contribute to their different drug deliveries. The crystallographic data presented in this work should be useful for designing new potent $\alpha$-adrenergic agents.

\section{Acknowledgments}

The technical assistance of Mrs. Tomoko Kawamura is gratefully acknowledged. This work was supported by Grants for the Key Technology Research Promotion Program of New Energy and Industrial Technology Development Organization (NEDO) of Japan and also by the Research and Study Program of Tokai University Educational System General Research Organization.

\section{References}

[1] A. L. Robin, I. P. Pollack, and J. M. deFaller, "Effects of topical ALO 2145 (p-aminoclonidine hydrochloride) on the acute intraocular pressure rise after argon laser iridotomy," Archives of Ophthalmology, vol. 105, no. 9, pp. 1208-1211, 1987.

[2] M. N. Burnett and C. K. Johnson, “ORTEPIII," Report ORNL6895, Oak Ridge National Laboratory, Oak Ridge, Tenn, USA, 1996.
[3] G. Byre, A. Mostad, and C. Romming, "Crystal and molecular structure of clonidine hydrochloride, 2(2,6 dichlorophenylamino) 2 imidazoline hydrochloride," Acta Chemica Scandinavica, vol. 30, no. 9, pp. 843-846, 1976.

[4] Mercury CSD 3.1 and Cambridge Crystallographic Data Centre, 2013, http://www.ccdc.cam.ac.uk/Solutions/CSDSystem/Pages/ Mercury.aspx.

[5] CrystalStructure, Version 4.0.1, Crystal Structure Analysis Package, Rigaku and Rigaku/MSC, 2010.

[6] A. Altomare, G. Cascarano, C. Giacovazzo et al., "SIR92-a program for automatic solution of crystal structures by direct methods," Journal of Applied Crystallography, vol. 27, no. 3, pp. 435-436, 1994. 

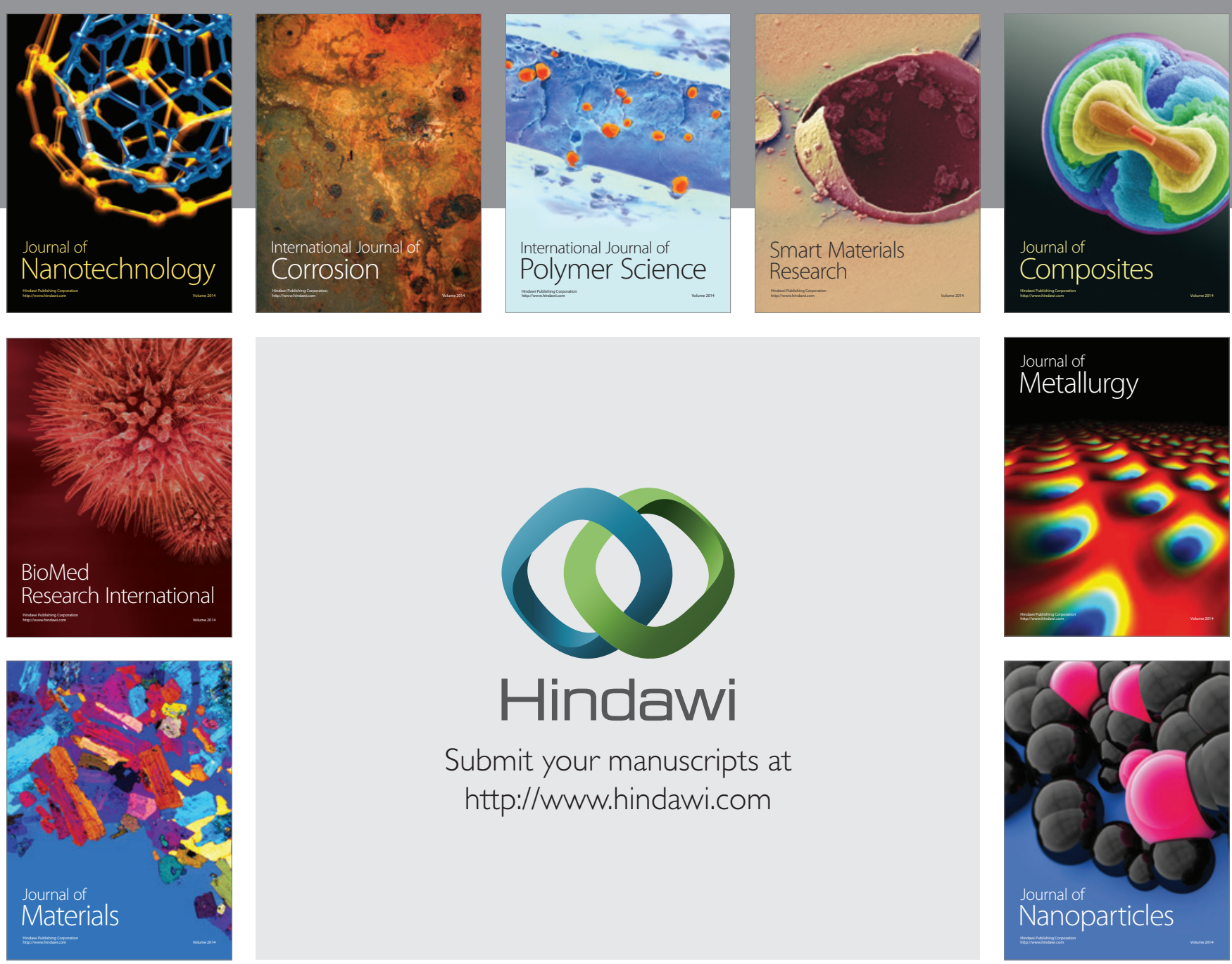

Submit your manuscripts at http://www.hindawi.com
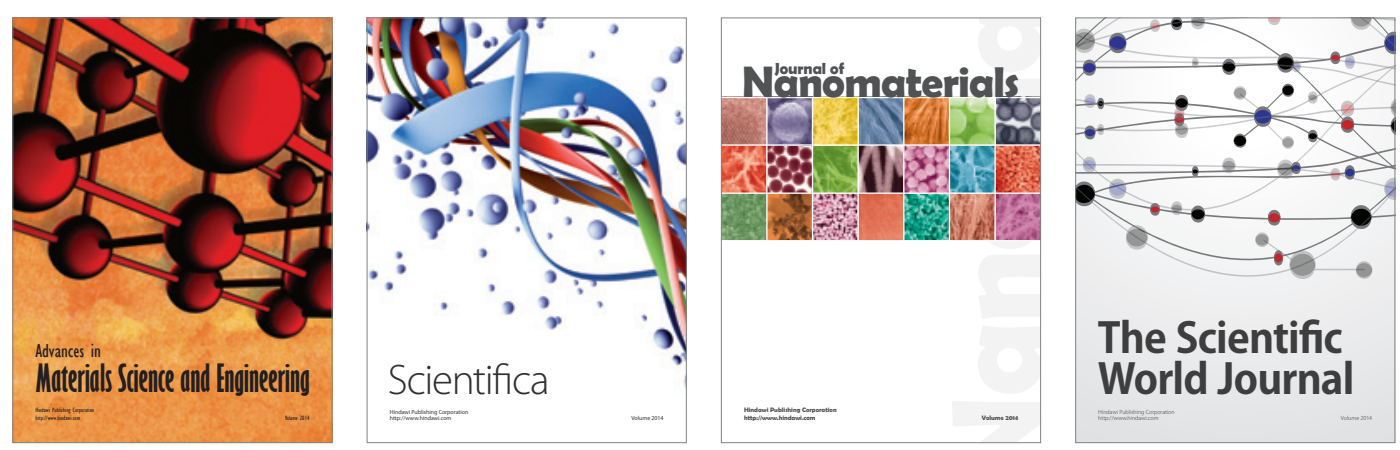

\section{The Scientific World Journal}
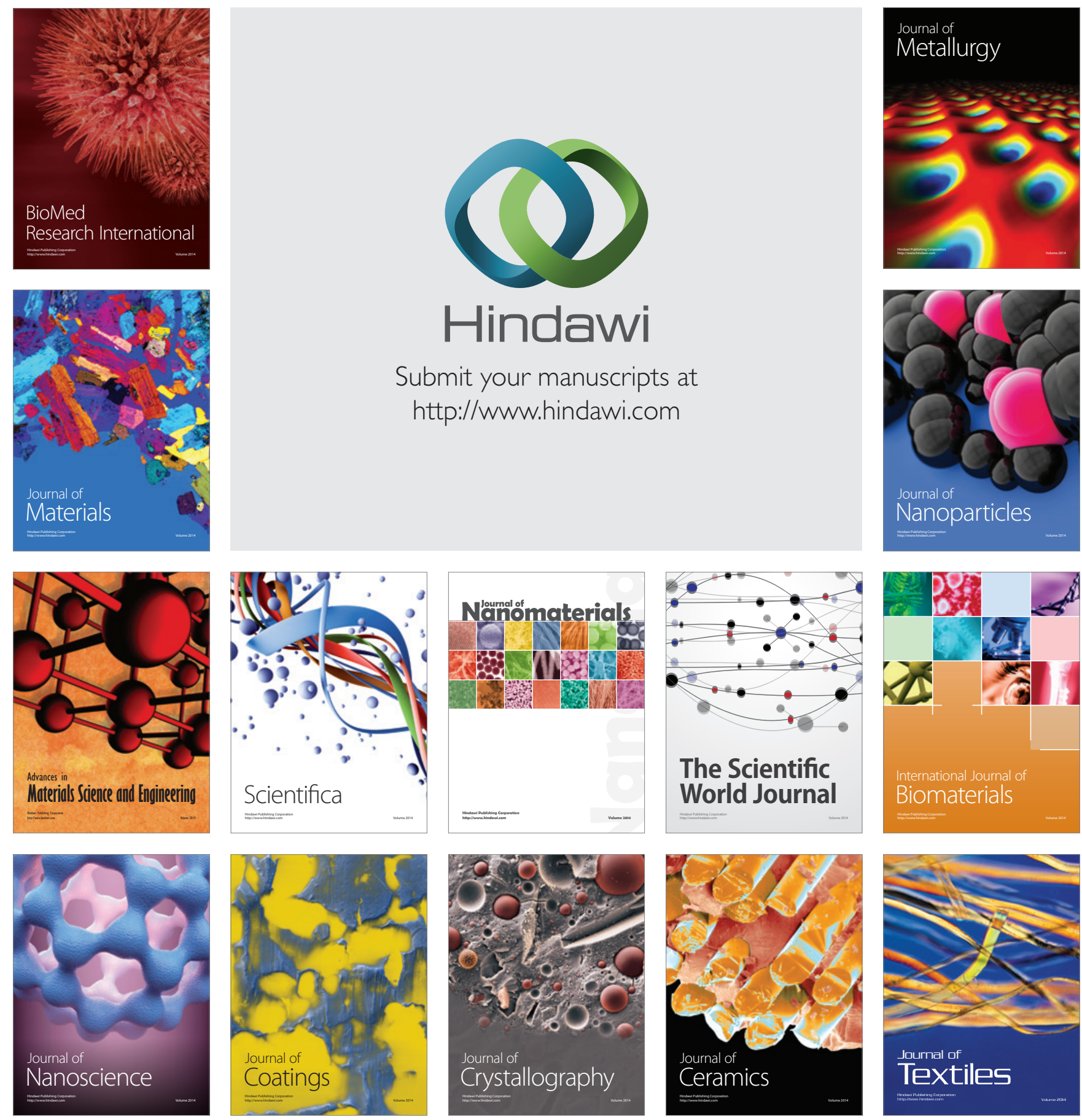